\title{
Pseudococcus comstocki (Kuwana) (Hemiptera: Pseudococcidae)'nin farklı sıcaklık koşullarında ve iki dut türü üzerinde gelişme ve üremesinin incelenmesi ${ }^{1}$
}

\author{
Investigations on biological characteristics of Pseudococcus comstocki (Kuwana) \\ (Hemiptera: Pseudococcidae) on different two mulberry species and different \\ temperatures ${ }^{1}$
}

\author{
Mustafa ATAŞ $^{2} \quad$ M. Bora KAYDAN ${ }^{3^{*}}$
}

\section{Summary}

Asiatic originated Pseudococcus comstocki (Kuwana), the Comstock mealybug (Hemiptera: Pseudococcidae) is polyphagous cosmopolite species. Nowadays it is spreading through to Europe and becoming wide distribution. In this study, the developmental time, survival and fecundity of $P$. comstocki on two mulberry species (Morus alba and M. nigra) (Moraceae) were studied at four different temperatures $\left(18 \pm 1,23 \pm 1,28 \pm 1\right.$ and $\left.20-32^{\circ} \mathrm{C}\right)$ and thermal constant was calculated. According to results, it appears that performance of $P$. comstocki and, consequently, its population increase were affected by feeding with different mulberry species and at different temperatures, and $M$. nigra seems to be more likely susceptible to the mealybug than $M$. alba in each temperatures because it displayed the highest performance on this host plant. The results showed that the population on $M$. nigra $\left(r_{\mathrm{m}}=0.123\right.$ female/female/day; $R_{0}=108.933$ female/female; $T_{0}=38.160$ day; $D T=5.639$ day) developed better than that on $M$. alba $\left(r_{m}=0.115\right.$ female/female/day; $R_{0}=84.281$ female/female; $T_{0}=38.600$ day; $D T=6.032$ day $)$ at $28^{\circ} \mathrm{C}$. It was found that there was an inverse relationship between the growth period of the population and the temperature, development of the mealybug becoming fully grown was the fastest on both Morus species at $28{ }^{\circ} \mathrm{C}$. The threshold for development $(\mathrm{t})$ and the thermal constant $(\mathrm{ThC})$ of the mealybug on $M$. nigra was determined as $7.87{ }^{\circ} \mathrm{C}, \mathrm{K}=513$ degree-days respectively; while on $M$. alba, these parameters were found to be $7.76{ }^{\circ} \mathrm{C}$ and $\mathrm{K}=518$ degree-days respectively.

Key words: Pseudococcus comstocki, thermal constant, development time, life table

\section{Özet}

Asya kökenli unlubit Pseudococcus comstocki (Kuwana) (Hemiptera: Pseudococcidae) polifag kozmopolit bir türdür. Son yıllarda Avrupa ülkelerinde hızla yayılan bu tür daha geniş bir dağılıma sahip olmaktadır. Bu çalışmada $P$. comstocki'nin farklı sıcaklık koşullarında $\left(18,23,28\right.$ ve $20-32^{\circ} \mathrm{C}$ ) ve iki farklı dut türü (Morus alba ve M. nigra) (Moraceae) üzerinde gelişme dönemlerinin süresi, ölüm oranları, üreme kapasitesi, dişi-erkek oranları, termal konstantı ve gelişme eşiğinin belirlenmesi amaçlanmıştır. Çalışma sonucunda $M$. nigra üzerinde beslenen popülasyonun $\left(r_{m}=0.123\right.$ dişi/dişi/gün; $R_{0}=108.933$ dişi/dişi; $T_{0}=38.160$ gün; $D T=5.639$ gün) M.alba üzerinde beslenen popülasyondan ( $r_{m}=0.115$ dişi/dişi/gün; $R_{0}=84.281$ dişi/dişi; $T_{0}=38.600$ gün; $D T=6.032$ gün) daha iyi geliştiği tespit edilmiştir. $P$. comstocki'nin sıcaklığa bağlı olarak gelişimi incelendiğinde türün en hızlı $28^{\circ} \mathrm{C}$ 'de ergin olduğu belirlenmiştir. Zararlının M. nigra'da gelişme eşiğinin (t) $7.87^{\circ} \mathrm{C}$, termal konstantının (ThC) $\mathrm{K}=513 \mathrm{gün}$-derece; M. alba'da gelişme eşiğinin (t) $7.76^{\circ} \mathrm{C}$, termal konstantının (ThC) $\mathrm{K}=518$ gün-derece olduğu saptanmıştır.

Anahtar sözcükler: Pseudococcus comstocki, termal konstant, gelişme süresi, yaşam çizelgesi

\footnotetext{
1 Bu çalışma 06-09 Nisan 2010 tarihinde Hanya, Girit, Yunanistan'da düzenlenen XII Intenational Symposium on Scale Insect Studies'de poster bildiri olarak sunulmuştur.

2 Diyarbakır Tarım II Tarım Müdürlüğü, Diyyarbakır

3 Çukurova Üniversitesi, İmamoğlu Meslek Yüksekokulu, Adana

Sorumlu yazar (Corresponding author) e-mail: bkaydan@cu.ed.tr

Alınış (Received): 23.09.2013～Kabul ediliş (Accepted): 06.01.2014
} 


\section{Giriş}

Tüm Dünyada ekonomik zararlı unlubit türleri arasında gösterilen Pseudococcus comstocki (Kuwana) (Hemiptera: Pseudococcidae), Asya kökenli bir tür olup şimdiye kadar Palearktik ve Nearktik Zoocoğrafik Bölge'lerde tespit edilmiştir (McKenzie, 1967; Ben-Dov et al., 2013; Kosztarab 1996). Polifag bir zararlı olan unlubitin, elma, armut, şeftali, dut ve bazı umbellifer türlerinde ciddi zarara neden olduğu bildirilmiştir (Bartlett, 1978; McKenzie, 1967). Avrupa'da ilk olarak İtalya'da kara dut ve şeftali, Fransa'da şehir ekosistemindeki dut türleri üzerinde tespit edilmiştir (Pellizzari et al., 2004; Kreiter \& Germain, 2005). P. comstocki ülkemiz'de ilk defa Kaydan \& Kozar, (2011) tarafından Iğdır'da dut (Morus alba L., Moraceae) üzerinde kaydedilmiş, daha sonra Artvin'de Nar (Punica granatum L., Lythraceae) (MBK kişisel gözlem) üzerinde bulunmuştur. $P$. comstocki diğer familya bireylerinde olduğu gibi bitkilerin dokularından bitki özsuyunu emmek suretiyle bitkileri zayıf düşürmekte, salgıladıkları tükürük salgılarından dolayı bitki dokularında deformasyonlara neden olmaktadır. Zararlı yoğun beslenme sonucu tatımsı madde salgılamakta ve bu tatıımsı maddeler üzerinde saprofit mantarların gelişmesi ile bitki üzerinde fumajin oluşumuna neden olmaktadır. Ayrıca $P$. comstocki bitki virüs hastalıklarına vektörlük eden türler arasında değerlendirilmekte bu nedenle bazı hallerde kendi zararından daha fazla ekonomik zararlara sebep olabilmektedir (Tidona \& Darai, 2011).

Ana vatanı Çin olan dut (Morus spp.) P. comstockinnin en önemli konukçularından biridir (Everett, 1960). Türkiye'de meyvesinden yararlanılan ve yaygın olarak yetiştirilen dut türleri Morus alba L. (beyaz dut), M. nigra L. (karadut) ve M. rubra L: (kırmızı veya mor dut)'dır (Karadeniz \& Şişman, 2003). Ülkemizde 2.130.000 adet meyve veren dut ağacından 50.000 ton ürün elde edilmektedir (Anonim, 2004). Meyvecilik kültürü çok eskilere dayanan Türkiye, dutun anavatanlarından ve doğal yayılış alanlarından biri olmasına karşın, bu genetik potansiyel yeterince değerlendirilememektedir. Meyve kalitesi bakımından oldukça üstün özelliklere sahip olan birçok genotip yalnızca kerestesinden yararlanmak amacıyla kesilerek yok edilmiştir (Erdoğan \& Pırlak, 2005).

Son yıllarda zararlılarla başarılı ile yürütülen mücadelede, sıcaklık ve gelişimin etkileşiminden yararlanarak her bir biyolojik döneminin, hangi zaman diliminde ortaya çıkacağı ve ne kadar süre görüleceği önem kazanmaktadır. Ancak, ilaçlamaların etkisiyle doğal düşman popülasyonlarının önemli ölçüde azalması, ikincil zararlıların ana zararlı durumuna geçmesi gibi bazı sorunlar ortaya çıkmaktadır. $\mathrm{Bu}$ nedenle entegre mücadelenin daha başarılı olabilmesi için zararlı türün sıcaklık ve gelişim etkileşiminden yararlanarak her bir biyolojik döneminin, hangi zaman diliminde ortaya çıkacağı ve ne kadar süre görüleceği önem kazanmaktadır. Bu bağlamda, böceklerin gelişme ve üremesini etkileyen en önemli etkenlerden ikisinin sıcaklık ve konukçu türü olduğu düşünüldüğünde, her iki etmenin böcek üzerindeki etkisinin bilinmesi söz konusu böcek ile mücadele stratejisinin belirlenmesinde çok önemli bir rol oynayacaktır. Nitekim, konukçunun kimyasal ve fiziksel özellikleri tercih edilme sebebini belirler (Price et al., 1980) ve konukçu bitki tercihi böceklerin biyolojisi ve gelişimi üzerine olumlu ya da olumsuz etkilerde bulunabilir. Bu yüzden üretim tercihlerimizi belirlerken, üretimini yapacağımız bitki üzerinde zararlı olan böceklerin biyolojilerini ve gelişmelerini iyi bilmemiz gerekir.

Bu çalışma ile $P$. comstocki'nin iki farklı konukçuda (M. alba, M. nigra) ve dört farklı sıcaklıkta (18, $23,28{ }^{\circ} \mathrm{C}$ sabit ve $20-32{ }^{\circ} \mathrm{C}$ değişken) biyolojik dönemlerinin süreleri, üreme kapasiteleri, erkek-dişi oranları, termal konstantı ve gelişme eşiklerinin ortaya çıkarılması amaçlanmıştır. Ayrıca, çalışma sonunda farklı sıcaklıklarda ve farklı konukçularda $P$. comstocki'nin biyolojik özellikleri belirlenerek hangi konukçuda ve hangi sıcaklıkta en iyi gelişim gösterdiğini tespit etmek, bununla birlikte gelişme eşiği ve ergin oluncaya kadar gerekli olan etkili sıcaklıklar toplamının belirlenmesi amaçlanmıştır. 


\section{Materyal ve Yöntem}

Çalışmanın ana materyalini $P$. comstocki ve ülkemizde yaygın olarak bulunan iki farklı dut türü ( $M$. alba ve M. nigra) oluşturmuştur.

Denemede kullanılacak dut türlerinin fidanları, içinde kum+gübre+toprak (1:1:1) karışımı bulunan $28 \mathrm{~cm}$ çapında ve $25 \mathrm{~cm}$ derinliğindeki saksıların içine alınıp $25 \pm 2{ }^{\circ} \mathrm{C}$ sıcaklık, \% 60-70 orantılı nem ve 14:10 saatlik aydınlık-karanlık koşullarındaki iklim odasında üretilmiştir.

Denemelerde kullanılacak stok kültürü oluşturmak için $P$. comstocki erginleri lğdır dut plantasyonlarından toplanarak laboratuvara getirilmiş ve getirilen bireyler patates yumruları ve kabak üzerine alınmıştır. Patatesler üzerinde tül ile kaplı havalandırma deliklerinin bulunduğu 5 litrelik plastik kavanozlarda muhafaza edilirken, kabaklar $1 \times 1 \times 1 \mathrm{~m}$ boyutlarında, ön tarafı tül ile kaplı cam fanuslarda muhafaza edilmişlerdir. Stok kültürler $\left(25 \pm 2{ }^{\circ} \mathrm{C}\right.$ sıcaklık, \% 60-70 orantılı nem ve 14:10 saatlik aydınlıkkaranlık) iklim odalarına konulmuş, stok kültürü devam ettirmek için kültürler iki haftada bir yenilenmiş ve deneme sonuna kadar muhafaza edilmiştir.

Denemelerin kurulum aşamasında unlubitin farklı sıcaklıklara $\left(18,23,28{ }^{\circ} \mathrm{C}\right.$ sabit ve $20-32{ }^{\circ} \mathrm{C}$ değişken sıcaklıkta) ve farklı konukçulara ( $M$. alba, $M$. nigra) adaptasyonunu sağlamak için $P$. comstocki'nin yumurtaları (genellikle bir yumurta kesesi içerisinde bulunan tüm yumurtalar) yaprak sapları, içinde su agarı bulunan Eppendorf tüplerine daldırılmış dut yaprakları üzerine bırakılmış ve bir döl süresince denemelerin yapılacağı konukçu ve sıcaklıkta beslenmeleri sağlanmıştır, söz konusu sıcaklık ve konukçularda ergin olan bireyler çiftleştirilip yumurta bırakmaları sağlanmıştır, daha sonra elde edilen yumurtalardan (adaptasyon sağlanmış döl) denemeler başlatılmıştır.

Farkı konukçularda ve sıcaklık koşullarında yetiştirilen $P$. comstocki popülasyonlarının biyolojik özelliklerinin belirlenmesi için farklı sıcaklıklar ve farklı konukçular üzerinde yetiştirilen popülasyonlardan elde edilen yumurtalardan çıkan birinci dönem larvalar içerisinde su agarı bulunan Petri kapları içerisinde yaprak alt yüzeyi üste bakacak şekilde yerleştirilmiş olan yaprak diskleri üzerine konulmuştur. Bireyler günlük olarak kontrol edilmiş ve deri değiştirme zamanları esas alınarak erkek ve dişi bireylerin ergin öncesi dönem süreleri, ergin dişi bireylere ait preovipozisyon, ovipozisyon ve postovipozisyon süreleri ile ergin dişilerin bıraktıkları yumurta sayıları kaydedilmiştir. Dişilerin yumurtlamasını sağlamak için dişiler ergin olur olmaz ergin erkekler ile bir araya konulmuş ve çiftleşmeleri sağlanmıştır. Bu denemeler sırasında agar üzerindeki yapraklar her 2 veya 3 günde bir değiştirilmiş ve bireylerin taze yapraklar üzerinde beslenmeleri sağlanmıştır. Denemeler en az 15 tekerrür olarak dizayn edilmiştir.

Farklı sıcaklıkların ve konukçuların $P$. comstocki'nin yumurta açılım oranına ve dişi-erkek oranlarına etkilerinin belirlenmesi amacıyla, farklı sıcaklıklarda ve konukçularda yetiştirilen popülasyonlardan yumurta keseleri içerisinde agar ve üzerinde yaprak bulunan Petri kaplarına alınmış, açılan ve açılmayan yumurtalar sayılmış, bu şekilde yumurtaların açılma oranı tespit edilmiş, açılan yumurtalar ergin oluncaya kadar beslenerek erkek dişi oranları kaydedilmiştir.

Farklı sıcaklıklarda ve farklı dut türleri üzerinde beslenen $P$. comstocki popülasyonlarına ait gelişme süreleri ve ergin ömrü ile ergine ait yumurta verimlerine ait veriler kullanılarak $P$. comstocki'nin farklı dut türleri üzerindeki yaşam çizelgeleri Birch (1948)'e göre hazırlanmıştır. Bu metoda göre,

$$
\Sigma \mathrm{I}_{\mathrm{x}} \cdot \mathrm{m}_{\mathrm{x}} \cdot \mathrm{e}^{-\mathrm{r} \cdot \mathrm{x}}=1
$$

eşitliği kullanılarak farklı popülasyonlara ait kalıtsal üreme yeteneği $(r)$ değeri hesaplanmıştır. Eşitlikteki; $I_{x}=$ yaşa bağlı canlılık oranını, $m_{x}=$ dişi başına bırakılan günlük dişi yumurta sayısını (dişi/dişi), 
e= doğal logaritma tabanını, r= kalıtsal üreme yeteneğini (dişi/dişi/gün), $x=$ dişi bireylerin gün olarak yaşını (gün) ifade etmektedir. Diğer bir yaşam çizelgesi parametresi olan Net üreme gücü $\left(R_{\circ}\right.$ (dişi/dişi/döl)),

$$
R_{0}=\Sigma I_{x} \cdot m_{x}
$$

formülü ile hesaplanmıştır. Bu veriler elde edildikten sonra ortalama döl süresi ( $T_{0}$ (gün)) aşağıdaki formüle göre belirlenmiştir.

$$
\mathrm{T}_{0}=\ln \mathrm{R}_{0} / \mathrm{r}
$$

Bir diğer parametre olan DT (Popülasyonun iki katına çıkması için gerekli olan süre),

$$
\mathrm{DT}=\ln (2) / \mathrm{r}
$$

formülü kullanılarak hesaplanmıştır.

Unlubitin farklı dut türleri üzerinde hesaplanan $r$ değerlerine çeşitlerin etkisinin önemli olup olmadığını test edebilmek için Jack-knife yönteminden yararlanıımıştır. Buna göre her çeşit üzerinde hesaplanan $r$ değerlerinden (Sokal \& Rohlf, 1981; Meyer et al., 1986'den yararlanarak),

$$
r_{j}=n \times r_{a l l}-(n-1) \times r_{i}
$$

eşitliği kullanılarak her bir $r$ değerinin hesaplanmasında yararlanılan tekerrür sayısı kadar yapay $r_{i j}$ değerleri üretilmiş ve daha sonra farklı konukçular üzerinde elde edilen veriler için t-test ikili karşılaştırma testi $(\alpha=0.05)$, farklı sıcaklıklarda elde edilen veriler için ise LSD testi uygulanarak karşılaştırmalar yapılmıştır.

Farklı konukçularda beslenen popülasyonlarından elde edilen gelişme süreleri, üreme kapasiteleri ve ergin ömür sürelerine ait veriler t-test analizine tabi tutularak, farklı sıcaklıklarda yetiştirilen popülasyonlara ait biyolojik özeliklere ait verileri ise ANOVA (Tek yönlü varyans analizi) kullanılarak test edilmiş, karşılaştırmalar LSD testi kullanılarak yapılmıştır $(\alpha=0.05)$.

Pseudococcus comstocki'nin gelişme eşiği ve termal konstant değerlerinin hesaplanması için $P$. comstocki'nin farklı sıcaklıklardaki gelişme süreleri kullanılarak, Campbell et al. (1974)'e göre gelişme eşiği ve yumurtadan ergin oluncaya kadar gerekli olan gün-derece değerleri tespit edilmiştir.

Bu modelde,

$$
V(T)=a+b T
$$

formülünde $T\left({ }^{\circ} \mathrm{C}\right)$ sıcaklık, $V(T)$ gelişme oranı, a ve b regresyon parametreleridir.

Gelişme eşiği $\left({ }^{\circ} \mathrm{C}\right) \mathrm{t}=-\mathrm{a} / \mathrm{b}$ formülü ile, termal konstant $\mathrm{K}$ (gün/derece)=1/b formülüne göre hesaplanmıştır.

Tüm istatistiksel analizler ve regresyon analizleri STATISTICA 8.0 paket programı kullanılarak yapılmıştır.

\section{Araştırma Sonuçları ve Tartışma}

Pseudococcus comstocki'nin dişi bireylerinin ergin öncesi gelişme süreleri her iki farklı konukçu üzerinde yetiştirilen popülasyonda da sıcaklık artışı ile birlikte kısalmıştır (Çizelge 1). Değişken sıcaklıkta yetiştirilen popülasyonlarda gelişme süresinde bir artış olmuş bu artışın sıcaklığın değişken olmasından dolayı meydana geldiği kanısına varılmıştır. Ergin öncesi gelişme süresi her iki Morus türü üzerinde de en kısa $28{ }^{\circ}$ C'de yetiştirilen popülasyonlarda tespit edilmiş $(M$. alba için $25.42 \pm 0.19$ gün; $M$. nigra için $25.20 \pm 0.24$ gün) olup bu değer istatistiki olarak diğer sıcaklıklarda yetiştirilen popülasyonlardan istatistiki 
olarak farklı bulunmuştur $\left(F_{(3,117)}=706.29 ; P \leq 0.05\right)$. Benzer durum $P$. comstockinin erkek bireylerinin ergin öncesi gelişme süreleri içinde gözlemlenmiş olup erkekler için ergin öncesi gelişme dönem süresi M. alba için $26.21 \pm 0.30$ gün, M. nigra için $26.02 \pm 0.19$ gün olarak belirlenmiştir. Bu değerler her iki dut türü üzerinde diğer sıcaklıklarda yetiştirilen popülasyonların gelişme süresi değerlerinden istatistiki olarak farklı bulunmuştur $\left(F_{(3,117)}=1230.3 ; P \leq 0.05\right)$ (Çizelge 2). Aynı sıcaklıkta farklı konukçularda yetiştirilen popülasyonların gelişme süreleri arasındaki farklılıklar hem dişi hemde erkek bireyler için istatistiki olarak farklı bulunmamıştır (Çizelge 2). Farklı dut türleri üzerinde beslenen popülasyonlarda dişilerin, sıcaklık değeri artıkça preovipozisyon, ovipozisyon, postovipozisyon süreleri ve ergin ömrünün kısaldığı gözlemlenmiştir (Çizelge 3). Farklı sıcaklıklarda yetiştirilen popülasyonlardan elde edilen dönem süreleri arasındaki farklııklar istatistiki olarak önemli bulunmuştur (Farklı sıcaklıklar sırasıyla $F_{(3,117)}=107.92$; $\left.P \leq 0.05 ; F_{(3,109)}=69.347, P \leq 0.05 ; F_{(3,117)}=35.065, P \leq 0.05 ; F_{(3,109)}=16.673 ; P \leq 0.05\right)$ (Çizelge 3). Bununla birlikte erkek toplam gelişme dönemine ait süreler aynı sıcaklıkta farklı konukçularda beslenen popülasyonlarda birbirlerinden farklı bulunmamıştır (Çizelge 3).

Ekolojik koşullar ve sıcaklık, bitki ve böcek guruplarının coğrafi dağılımlarını, komünite içindeki yoğunluklarını ve biyolojilerini direkt olarak etkileyen faktörlerin başında gelmektedirler. Bu çalışmada sıcaklık artışı ile birlikte $P$. comstockinin gelişme sürelerinde önemli oranlarda kısalma kaydedilmiştir. Toplam gelişme $28^{\circ} \mathrm{C}$ 'de 25 gün sürerken, $18^{\circ} \mathrm{C}$ 'de 49 günde tamamlanmıştır. $P$. comstocki'nin preovipozisyon, ovipozisyon, postovipozisyon ve ergin ömrü değerlerinde de benzerlikler görülmüştür. Heidari (1999), Chong et al. (2003), Jeon et al. (2003), Huang et al. (2005), farklı unlubit türlerinin sıcaklık artışı ile birlikte gelişimlerinin hızlandığını bildirmişlerdir. Bodenheimer (1951), İsrail'de yapmış olduğu bir çalışmada $P$. citri'nin bir dölünü $30^{\circ} \mathrm{C}$ 'de 15.7 günde, $20^{\circ} \mathrm{C}$ 'de ise 29.1 günde tamamladığını bildirmiştir. Kim et al. (2008), Pseudococcus cryptus Hempel (Hemiptera: Pseudococcidae) un dişilerinde ömür uzunluklarına $16^{\circ} \mathrm{C}$ ' de 80.4 gün, $32^{\circ} \mathrm{C}$ ' de 31.3 gün olduğunu, preovipozisyon ve ovipozisyon süreleri arasında da benzerlikler olduğu saptanmıştır.

Farklı sıcaklıkların ve farklı konukçuların $P$. comstocki'nin toplam yumurta verimine etkisi oldukça belirgindir. Bir dişi tarafından bırakılan yumurta sayısı en düşük $18^{\circ} \mathrm{C}$ 'de $M$. alba üzerinde 99.87 adet, en yüksek yumurta sayısı ise $28^{\circ} \mathrm{C}$ 'de $M$. nigra üzerinde 209.28 adet olarak tespit edilmiştir. $18^{\circ} \mathrm{C}$ 'de farklı konukçularda beslenen popülasyonlarda dişilerin bıraktığı toplam yumurta sayıları arasındaki farklılıklar istatistiki olarak farklı bulunmamış $\left(\mathrm{t}_{(1,32)}=1.466 ; \mathrm{P} \geq 0.05\right)$, fakat diğer sıcaklıklarda beslenen popülasyonlarda bu fark önemli bulunmuştur $\left(23^{\circ} \mathrm{C}\right.$ için $\left(t_{(1,58)}=4.450 ; P \leq 0.05\right) ; 28^{\circ} \mathrm{C}$ için $\left(t_{(1,79)}=8.185\right.$; $\mathrm{P} \leq 0.05) ; 20-32^{\circ} \mathrm{C}$ için $\left(\mathrm{t}_{(1,57)}=3.064 ; \mathrm{P} \leq 0.05\right)$ ) (Çizelge 4). Benzer şekilde yapılan çalışmalarda Chong et al. (2008), Maconellicoccus hirsutus (Green)'un Japon gülü üzerinde yaptıkları çalışmada unlubitin bıraktığı toplam yumurta sayısı 20 ile $27^{\circ} \mathrm{C}$ arasında $260-300$ adet iken bu sayı $30^{\circ} \mathrm{C}$ 'de 100 adet dolaylarında tespit edilmiştir. Kim et al. (2008), P. cryptus'un $28^{\circ} \mathrm{C}$ 'de 111 adet, $32^{\circ} \mathrm{C}$ 'de 102 adet yumurta verdiğini tespit etmişlerdir. Bırakılan toplam yumurta sayısını etkileyen en önemli faktörlerden birinin sıcaklık olduğu görülmektedir (Çizelge 4).

Sıcaklık artışı ile birlikte $P$. comstockinnin yumurta açılma sürelerinin kısaldığı kaydedilmiştir. $18^{\circ} \mathrm{C}$ 'de yumurta açılma süresi 16.3 gün olarak belirlenirken $28^{\circ} \mathrm{C}$ 'de 6.6 gün olarak belirlenmiştir (Çizelge 1). Buna ek olarak sıcaklık artışı ile birlikte yumurtaların açılma oranlarında ise belirgin şekilde bir artış tespit edilmiştir (Çizelge 4). Benzer şekilde Heidari (1999), Chong et al. (2003), bazı unlubit türlerinin yumurta açılma süresinin sıcaklık artışıyla ters orantılı olduğunu saptamışlardır. Kim et al. (2008), $P$. cryptus'un yumurta açılma sürelerini 16,28 ve $32^{\circ} \mathrm{C}$ sıcaklıklarda sırasıyla $54.9,17.4$ ve 19.3 gün olarak tespit etmişlerdir. $P$. comstocki üzerinde üçü sabit $(18,23$ ve 28) biri değişken (20-32) olan dört farklı sıcaklıkta yaptığımız çalışmada $18,23,28$ ve $20-32^{\circ} \mathrm{C}$ sıcaklıklarda sırasıyla popülasyonda dişi bireylerin oranı \%37, \%43, \%52 ve \%42 bulunmuştur (Çizelge 4). Heidari (1999) patates üzerinde yetiştirilen $P$. comstocki'nin farklı sıcaklıklarda, $30^{\circ} \mathrm{C}$ 'de erkek dişi oranının dişi lehine olduğunu tespit etmiştir. Polat et al. (2007) farklı konukçuların Turunçgil unlubiti popülasyonlarında erkek dişi oranlarında farklılıklar meydana getirdiğini bildirmişlerdir. Birbirinin benzeri olan bu çalışmalarda erkek/dişi oranının farklıığının konukçu bitki türünden kaynaklandığı düşünülmektedir. 

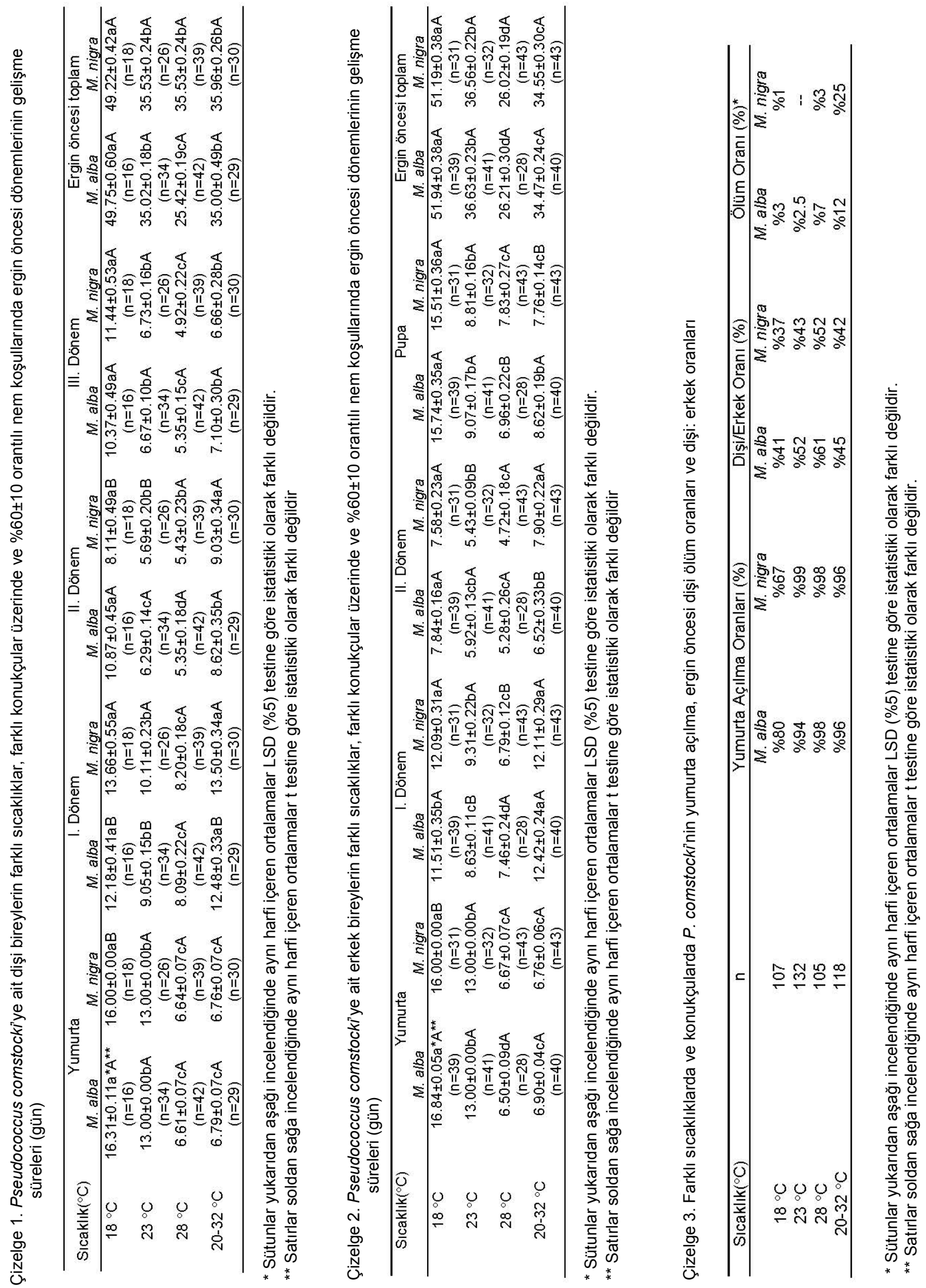

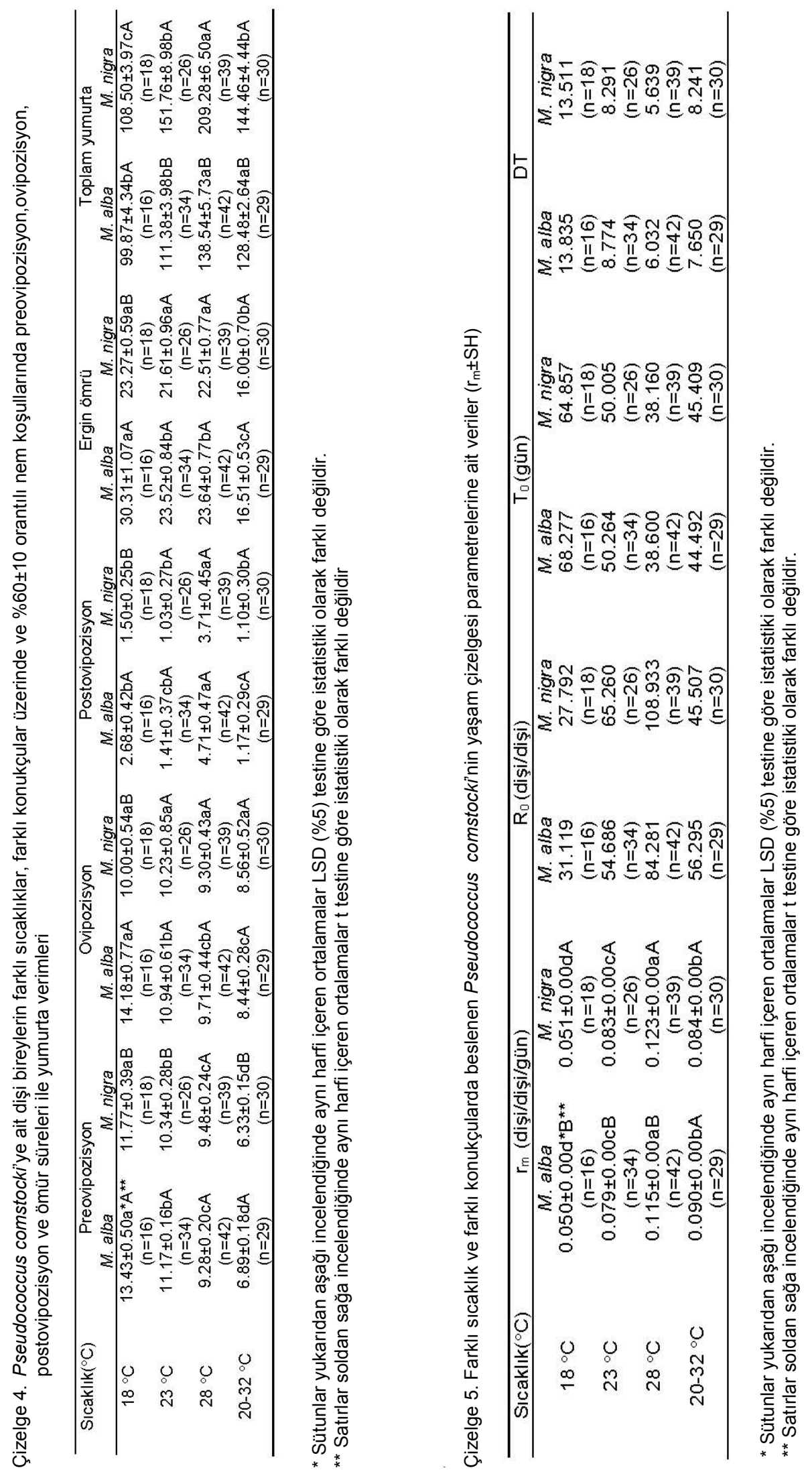
Farklı sıcaklıklarda ve farklı dut türleri üzerinde beslenen $P$. comstocki popülasyonlarının gelişme sürelerine ait veriler, ergin ömrü süreleri ve bıraktıkları günlük yumurta sayıları verileri birleştirilerek elde edilen yaşam çizelgeleri ve bu yaşam çizelgelerine ait parametreler Çizelge 5 ve Şekil 1'de görülmektedir. Buna göre $P$. comstocki'nin en erken $28^{\circ} \mathrm{C}$ 'de her iki dut türünde de 33. günde yumurtlamaya başladığı görülmüştür. 20-32 ${ }^{\circ} \mathrm{C}$ 'de $M$. alba'da 36., M. nigra'da 37. günde; $23{ }^{\circ} \mathrm{C}$ 'de her iki dut türünde de 45. günde; $18^{\circ} \mathrm{C}$ 'de $M$. nigra'da 57. günde, en geç olarak da $18^{\circ} \mathrm{C}$ 'de $M$. alba üzerinde 62 . günde yumurtlamaya başladığı belirlenmiştir. $P$. comstocki'nin kalıtsal üreme yeteneği $\left(r_{\mathrm{m}}\right)$ değerlerinin $18^{\circ} \mathrm{C}$ 'de M. alba'da 0.050 dişi/dişi/gün, $M$. nigra'da 0.051 dişi/dişi/gün olduğu belirlenmiş olup aralarındaki farklııklar istatistiki olarak farklı bulunmuştur $\left(\mathrm{t}_{(1,45)}=2.709\right.$; $\left.\mathrm{P} \leq 0.05\right)$. Farklı sıcaklıklarda aynı konukçulara yetiştirilen $P$. comstocki popülasyonları karşılaştırıldığında, sıcaklık artışı ile birlikte $r_{m}$ değerlerinin de yükseldiği belirlenmiş ve aralarındaki farklıklar istatistiki olarak farklı bulunmuştur $\left(F_{(3,125)}=411.79, P \leq 0.05\right)$ (Çizelge 5). Genel olarak aynı sıcaklıkta farklı dut türleri üzerinde beslenen popülasyonlarda elde edilen rm değerlerinin $M$. nigra üzerinde beslenen popülasyonlarda $M$. alba üzerinde beslenen popülasyonlarda elde edilen değerden daha yüksek olduğu tespit edilmiştir. Net üreme gücü $\left(R_{0}\right)$ en yüksek değeri $28^{\circ} \mathrm{C}$ 'de 108.933 dişi/dişi/döl olarak $M$. nigra türü üzerinde tespit edilmiştir. Net üreme gücünün en düşük değeri ise $M$. nigra üzerinde $18^{\circ} \mathrm{C}$ 'de 27.792 dişi/dişi/döl olarak tespit edilmiştir. ( $\left.T_{0}\right)$ döl süresi $18^{\circ} \mathrm{C}^{\prime}$ de $M$. alba üzerinde beslenen popülasyonda 68.277 günle en uzun bulunurken, $28^{\circ} \mathrm{C}$ 'de $M$. nigra üzerinde 38.160 günle en kısa olduğu bulunmuştur (Çizelge 5). Popülasyonların iki katına çıkması için gerekli süreleri değerlendirecek olursak, (DT) süresi en uzun 13.835 günle $18^{\circ} \mathrm{C}$ 'de $M$. alba üzerinde tespit edilmiş olup, (DT) süresinin en kısa olduğu sıcaklık ve konukçu ise 5.639 günle $28^{\circ} \mathrm{C}$ tespit edilmiştir (Çizelge 5). Konukçu bitki çeşidinin böcek biyolojisine ve üremesine etkisinin belirlenmesinde net üreme gücü $\left(R_{0}\right)$ ve kalıtsal üreme yeteneği $\left(r_{m}\right)$ çok önemli göstergelerdir (Kaydan et al., 2004). Yapılan bu çalışmada, zararlının en iyi gelişim gösterdiği $28^{\circ} \mathrm{C}^{\prime}$ de hem net üreme gücü hem de kalıtsal üreme yeteneği $\left(R_{0}=108.933\right.$ dişi/dişi/döl; $r_{m}=0.123$ dişi/dişi/gün) $M$. nigra üzerinde beslenen popülasyonlarda M. alba üzerinde beslenen poülasyonlara göre daha yüksek çıkmıştır. Bu çalışmaya benzerlik gösteren çalışmalarda gerek unlubitlerin gerekse diğer böcek guruplarının beslendiği konukçuların hem net üreme gücüne hem de kalıtsal üreme yeteneğine etkide bulunduğu belirtilmiştir (Marohasy, 1997; Heidari, 1999; Chong et al., 2003; Jeon et al., 2003; Huang et al., 2005; Kim et al., 2008).

Morus alba üzerinde yumurta bırakılmasından ergin oluncaya kadar geçen sürelerin linear regresyon denklemi $y=-0.0149+0.0019$.x olarak hesaplanmıştır $\left(r^{2}=0.9948 ; P \leq 0.05\right)$. Oluşturulan bu formüle göre $P$. comstocki'nin gelişme eşiği $t=7.76^{\circ} \mathrm{C}$ olarak tespit edilmiş olup yumurtadan ergin oluncaya kadar gerekli olan gün-derece toplamı $\mathrm{K}=518$ gün-derece olarak belirlenmiştir. Bu denklem $M$. nigra üzerinde yetiştirilen popülasyonda $y=-0.0153+0.0019 . x$ olarak oluştulmuştur $\left(r^{2}=0.9874 ; P \geq 0.05\right)$. $\mathrm{Bu}$ denkleme göre $P$. comstocki'nin gelişme eşiği $\mathrm{t}=7.87^{\circ} \mathrm{C}$ olarak tespit edilmiş olup yumurtadan ergin oluncaya kadar gerekli olan gün-derece toplamı $\mathrm{K}=513$ gün-derece olarak tespit edilmiştir. Walton ve Pringle (2005), Planacoccus ficus Signoret (Hemiptera: Pseudococcidae) un gelişme eşiğini $16.9^{\circ} \mathrm{C}$ olarak bildirmiş ve $P$. ficus'un bir dölünü tamamlaması için gerekli gün-derece değerinin 203 olarak tespit etmişlerdir. (Mendel \& Blumberg, 2004), Planacoccus citri'nin gelişme eşiğini $12-13^{\circ} \mathrm{C}$ ve yumurtadan ergin oluncaya kadarki gerekli olan gün-dereceyi 500 gün-derece olarak bildirmişlerdir. Kim et al. (2008), Pseudococcus cryptus'un etkili sıcaklıklar toplamını (termal konstant) $\mathrm{K}=316.6$ gün-derece olarak tespit etmişlerdir. Heidari (1999), patates üzerinde $P$. comstocki'nin yumurtadan ergin oluncaya kadar intiyaç duyduğu gün-derece toplamını K= 523 gün- derece olarak hesaplamıştır. Bu çalışmada elde edilen değerler yapılan çalışmalar ile paralellik göstermektedir. 

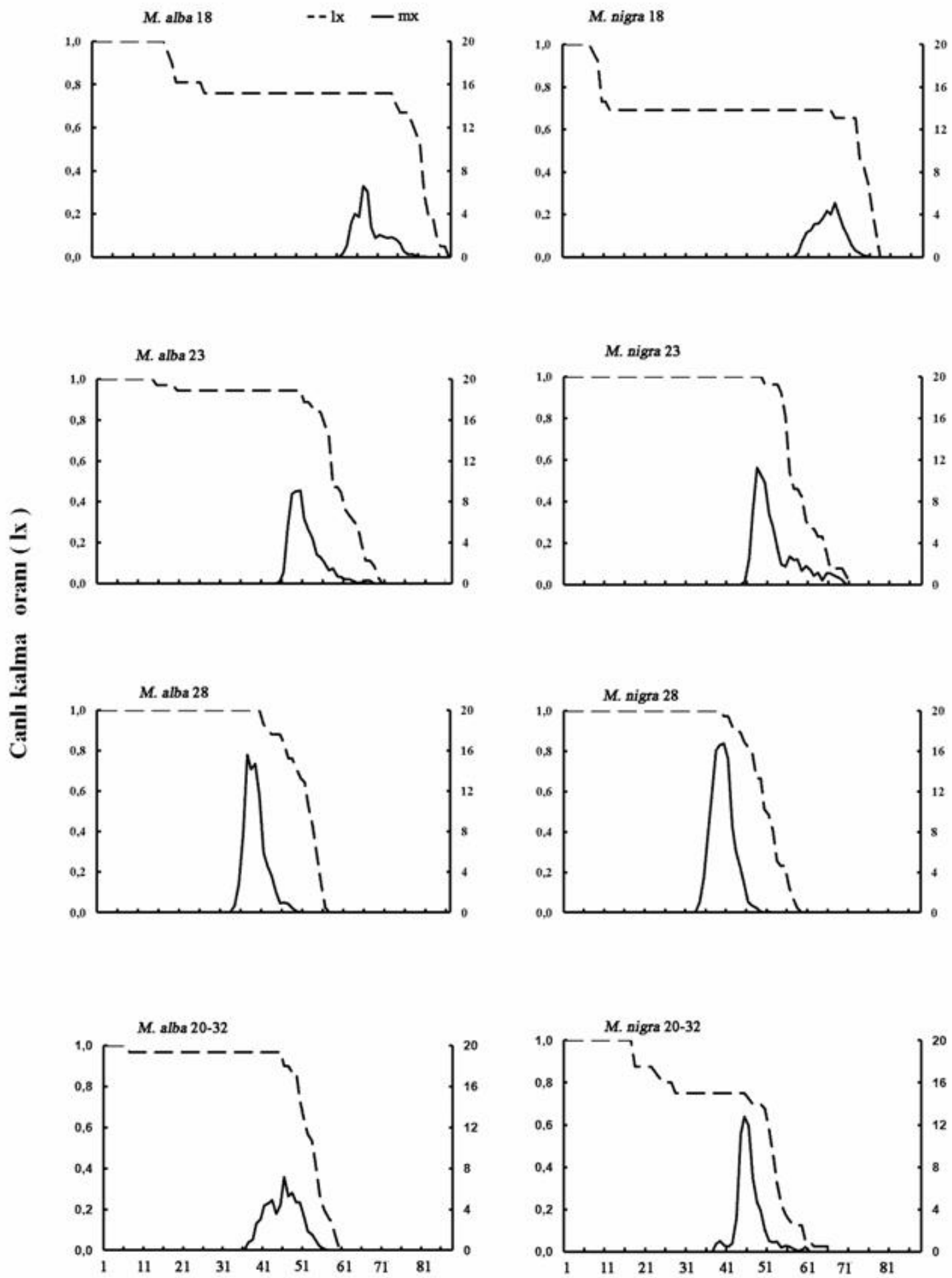

先

\section{Yaș ( günler )}

Şekil. 1. Farklı Konukçularda ve sıcaklıklarda yetiştirilen Pseudococcus comstocki popülasyonlarının yaşam çizelgeleri. 
Sıcaklık değişimleri bütün canlı guruplarını etkilemekte ve sonuçları bazı canlı guruplarında kısa sürede gözlemlenebilirken bazı canlı guruplarında bu etki uzun zaman sonra kendini gösterebilmektedir. Organizma gurupları arasında sıcaklık değişimlerinden en çok böceklerin etkilendikleri belirlenmiştir. Çünkü sıcaklığın böceklerin gelişmelerinde, üremelerinde ve hayatta kalma oranlarında büyük bir rolü bulunmaktadır. Böceklerin hayat döngülerinin genelde kısa olması ve yüksek üreme kapasitesine sahip olmaları sebebiyle sıcaklık önemli bir etken haline gelmektedir. Bu yüzden böcekler sıcaklık değişimlerine bitkiler ve omurgalı hayvanlar gibi uzun yaşayan organizmalardan daha çok ve çabuk tepki verirler.
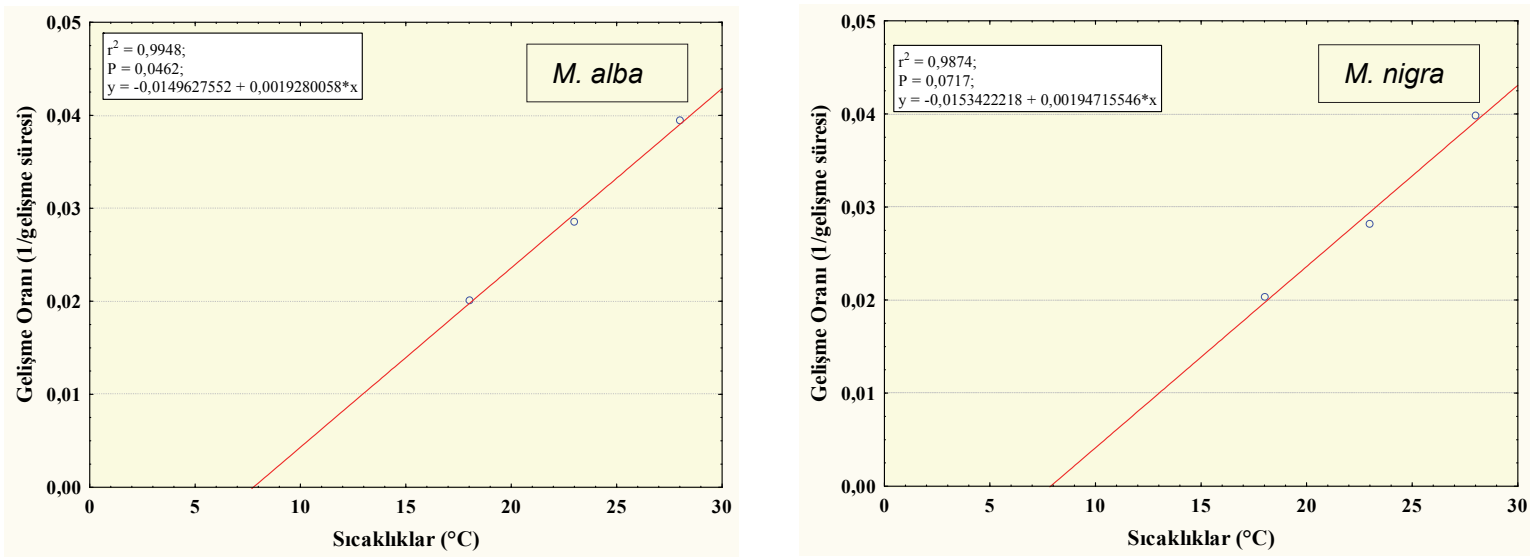

Şekil 2. Farklı sıcaklıklarda Morus alba ve Morus nigra üzerinde yetiştirilen Pseudococcus comstocki popülasyonundaki dişilerin sıcaklığa bağlı gelişim oranları (Regresyon denkleminde gelişme sürelerinin ortalamaları kullanılmıştır).

Sonuç olarak yapılan bu çalışmada $P$. comstocki'nin en iyi ve en hızlı gelişimini $28^{\circ} C^{\prime}$ de gerçekleştirdiği, M. nigra' üzerinde daha iyi geliştiği belirlenmiştir. Gelişimini tamamlamak için 513 gündereceye intiyacı olduğu tespit edilmiştir. Bu çalışmayla elde edilen veriler erken uyarı ve tahmin sistemlerinde kullanılarak zararlı ile mücadelede en uygun zamanın belirlenmesinde faydalı olacağı düşünülmektedir.

\section{Teşekkür}

Çalışma YYÜ Bilimsel Araştırma Projeleri Birimi tarafından desteklenmiştir (2008-FBE-YL026). Yayının taslak aşamasında görüş ve önerilerini esirgemeyen sayın Yrd. Doç. Dr. Murat Muştu'ya ve Prof. Dr. Remzi ATLıHAN'a teşekkürü bir borç biliriz. Çalışmanın yapımı sırasında desteklerini esirgemeyen sayın Evin POLAT AKKÖPRÜ'ye katkılarından dolayı teşekkür ederiz.

\section{Yararlanılan Kaynaklar}

Anonim, 2004. Tarımsal Yapı (Üretim, Fiyat, Değer). T.C. Başbakanlık Devlet İstatistik Enstitüsü

Bale, J.S., G.J. Masters, I.D. Hodkinson, C. Awmack, T.M. Bezemer, V.K. Brown, J. Butterfield, A. Buse, J.C. Coulson, J. Farrar, J.E.G. Good, R. Harrington, S. Hartley, T.H. Jones, R.L. Lindroth, M.C. Press, I. Symrnioudis, A.D. Watt and J.B. Whittaker, 2002. Herbivory in global climate change research: direct effect of rising temperature on insect herbivores. Global Change Biology, 8(1): 1-16.

Bartlett, B.R. 1978. "Pseudococcidae. 137-170". In: Introduced Parasites and Predators of Arthropod Pests and Weeds: a World Review (Ed.: C.P. Clausen),. Agricultural Research Service, United States Department of Agriculture, Washington, D.C.. $545 \mathrm{pp}$.

Ben-Dov Y., D.R. Miller, \& G.A.P. Gibson, 2013. ScaleNet: A database of the scale insects of the world. (Web page: http://www.sel.barc.usda.gov/scalenet/scalenet.htm) (Accessed date: May 2013).

Birch, L.C., 1948. The intrinsic rate of natural increase of an insect population. Journal of Animal Ecology, 17: 15-26 
Bodenheimer, F.S., 1951. Citrus Entomology in the Middle East. Junk, The Hague.

Campbell, A., B.D. Frazer, N. Gilbert, A.P. Gutierrez \& M. Mackauer, 1974. Temperature requirements of some aphids and their parasites. Journal of Applied Ecology, 11: 431-438.

Chong, J. H., R. D. Oetting \& M. W. Van lersel, 2003. Temperature effects on the development, survival, and reproduction of the Madeira mealybug, Phenacoccus madeirensis Green (Hemiptera: Pseudococcidae), on chrysanthemum. Annals of Entomological Society of America, 96(4):539-543.

Chong, J. H., A. L. Roda \& C. M. Mannion,. 2008. Life history of the Mealybug, Maconellicoccus hirsutus (Hemiptera: Pseudococcidae), at constant temperatures. Entomological Society of America., 37(2): 323-332.

Erdoğan, Ü. \& L. Pırlak, 2005. Ülkemizde dut (Morus spp.) üretimi ve değerlendirilmesi. Alatarım, 4(2): 38-43.

Heidari, M., 1999. The intrinsic rate of increase and temperature coefficients of the Comstock mealybug, Pseudococcus comstocki (Kuwana) (Hemiptera: Coccoidea: Pseudococcidae). Entomologica, 33: 297-303.

Huang, L.C., M.L. Zhang, X.M. Song, L. Zhao \& Y. Yang, 2005. The occurrence regulation of Pseudococcus comstocki in apple orchard. China Fruits, 4: 32-34.

Jeon, H.Y., D.S. Kim, M.R. Cho, Y.D. Chang \& M.S. Yiem, 2003. Temperature-dependent development of Pseudococcus comstocki (Homoptera: Pseudococcidae) and its stage transition models. Korean Journal of Applied Entomology, 42(1): 43-51.

Karadeniz, T. \& T. Şişman, 2003. "Beyaz ve karadutun meyve özellikleri ve çelikle çoğaltılması, 428-432". Ulusal Kivi ve Üzümsü Meyveler Sempozyumu (23-25 Ekim), Ordu.

Kim, S. C., J. Song, H. \& D. S. Kim, 2008., Effect of temperature on the development and fecundity of the Cryptic Mealybug, Pseudococcus cryptus, in the laboratory, Journal of Asia-Pacific Entomology, 11(3): 149-153.

Kosztarab, M,. 1996. Scale insects of Northeastern North America: Identification, biology, and distribution. Virginia Museum of Natural History, Martinsburg, Virginia. 650 pp.

Marohasy, J., 1997. Acceptability and suitability of seven plants species for the mealybug Phenacoccus parvus. Entomologia Experimentalis et Applicata, 84: 239-246

McKenzie, H.L., 1967. Mealybugs of California with taxonomy, biology, and control of North American species (Homoptera: Coccoidea: Pseudococcidae). Univ. Calif. Press, Berkeley. 526 pp.

Meyer, J. S.; C. G. Ingersoll, L. L. Mcdonald \& M. S. Boyce, 1986. Estimating uncertainty in population growth rates: jackknife vs. bootstrap techniques. Ecology, 67: 1156-1166.

Pellizzari, G., 2005. New, potentially dangerous scale insects in Italy: Fiorinia pinicola Maskell, Pseudococcus comstocki (Kuwana), and Peliococcus turanicus. Informatore Fitopatologico, 6: 20-26.

Price, P. W., C.E. Bouton, P. gross, B. A. McPheron, J. N. Thompson \& A. E. Weis. 1980. Intaractions among three trophic levels: influence of plant interactions between insect herbivores and naturel enemies. Ann. Rev. Ecol. Syst., 11: 41-65.

Polat F., S. Ülgentürk \& M. B. Kaydan, 2007. Developmental biology of citrus mealybug, Planococcus citri (Risso) (Hemiptera: Pseudococcidae) on ornamental plants. XI International Symposium on Scale Insect Studies (2427 September), Oeiras, Portugal.

Sokal, R. R. \& F. J. Rohlf, 1981. Biometry. The Principles and Practise of Statistics in Biological Research. New York, $843 \mathrm{pp}$.

Tidona C. \& G. Darai, 2011. The Springer Index of Viruses. Springer Press, 2088 pp.

Walton V. M. \& K. L. Pringle, 2005. Developmental biology of vine mealybug, Planococcus ficus (Signoret) (Homoptera: Pseudococcidae), and its parasitoid Coccidoxenoides perminutus (Timberlake) (Hymenoptera: Encyrtidae). African. Entomology, 13: 143-147. 
